\title{
Clara Law's Floating Life and Hong Kong-Australian 'flexible citizenship'
}

\author{
Tony Mitchell
}

\begin{abstract}
Clara Law's film Floating Life was the first Australian film to be nominated for an Oscar for Best Foreign Film, and the first Australian film to deal with migrant Hong Kong Chinese identities 'from inside'. From perspectives of transnational Chinese migration and flexible citizenship, this article looks at Floating Life as a Hong Kong Chinese migrant reading of Australia, which defamiliarizes and recontextualizes familiar Australian localities and geopolitical formations, contrasting them with the film's other principal loci of Hong Kong and Germany. It also interprets the film as a neo-Confucian study of family disintegration in a migrant context, and an exploration of notions of home and identity.
\end{abstract}

Keywords: Transnational; Hong Kong Cinema; migration; neo-Confucianism; identity.

\section{Floating lives, Australian core culture and liminality}

Hong-Kong Australian director Clara Law's 1997 film Floating Life, about the transmigration experiences of the Chans, a Hong Kong Chinese family in Australia and Germany, has achieved the status of a major cultural text about the dilemmas, struggles and self-management strategies of 'Asian' migrants in Australia. The film's title has become a metaphor for the double displacement, deterritorialization and dislocation experienced by many Chinese diasporic and South Asian migrants in Australia, and in this guise was mobilized for the title (but little else) of Floating Lives, an ethnographic study of media use among Asian immigrants in Australia by Stuart Cunningham, John Sinclair and other participants (2000) in a project entitled Audiovisual Media Use for Cultural Maintenance and Negotiation by Diasporic Communities of Asian Origin in Australia'. As a study of diasporic Thai, Fijian Indian, Southeast Asian Chinese and Vietnamese media use in Australia, 
Floating Lives remains grounded in a literal, reductive and largely negative reading of the film's title in which, as Tania Dreher has rightly suggested, its study of media use within circumscribed migrant communities involves 'negotiating cultural identity through media' posited largely as a task for diasporic subjects, adapting to new surroundings within an unmarked and largely unchanging "Australian" core culture' (2000, p. 259). Floating Life, on the other hand, is a study of a fictional Hong Kong Chinese family who transmigrate to Australia in an extension of what Ong has called 'the Pacific shuttle' $(1999$, p. 110) and struggle to adapt to new surroundings, eventually managing to establish their own traditionally-based Chinese cultural and spiritual locus with little need for any direct negotiation with 'Australian core culture'.

The film was also invoked, albeit tangentially, by Philip Mar in his 1998 article about the transcultural experiences of Hong Kong migrants in Sydney, drawing on interviews with a number of (mostly female) subjects, which, like the film, focuses on 'the subjectivities of Hong Kong emigrants and their capacity to deal with the often paradoxical exigencies of a transnational "floating life" (1998, p. 72). I shall compare some of Mar's empirical findings more closely with the migrant experiences portrayed in the film in an attempt to suggest less tentative conclusions than he does about the transnational identities of his interviewees. In the process, I shall outline a different reading of Floating Life from David Eng (1999a), who has characterized the film in terms of Freudian melancholia and loss in relation to racial difference and assimilation. Eng suggests that the film reflects the emergence of a postcolonial Hong Kong subjectivity - drawing on Abbas' notion of the déjà disparu (1997) - precisely at this moment of forfeiture and loss - through an inexorable logic of melancholic incorporation and identification that the vocabulary of diaspora, exile, and dispersion continually traces in its language of lost origins' (Eng 1999, p. 132). My reading of the film gives less emphasis to loss and melancholia, and attempts to reconcile the Chan family's experiences with Law's own statements about the film at the 1996 Pardo film festival in Switzerland. These suggest an existential dimension which offers interesting tensions between Law's own position as a 'cosmopolitan' film director and the more anchored material, psychological and ancestral dilemmas of the characters in the film:

Floating Life describes most aptly for me the world of an immigrant. An immigrant is cut off from history, both from one's personal history and the nation's history. $\mathrm{He} / \mathrm{Sh}$ has to learn to live "floatingly". What does existence mean away from one's country, the nonexistence of an existence when one is cut off from one's roots? Yet aren't we all transient beings passing through this place called Earth? (Law 1996) 


\section{Tony Mitchell}

This notion of a perpetually transient state of 'living floatingly' hints at a positive reading of diasporic migrant mobility and flexibility which operates independently from nation-states in constructing a fluid sense of identity which is able to benefit from liminality. Arguably, it also suggests possibilities for resolution of the traumas of the migrant experience which the narrative progression of Floating Life indicates and which this article will explore, reaching towards Ong's concept of 'flexible citizenship' (1999) and Appadurai's notion of a transnational identity that does not 'depend on the isomorphism of citizenship with cultural identity, of work with kinship, of territory with soil, or of residence with national identification' $(1998$, p. 449). This is also a means of contesting other readings of the film, such as Roxburgh's (1997), which seems determined to place it within notions of an 'Australian Self' derived from national cinematic canons and link it to other Australian films which deal with non-Anglo-Australian migrants as victims of a repressive, intolerant nation-state. As Audrey Yue has indicated, Floating Life 'is multilingual, transnational and mobile; its themes of displacement and alienation highlight the diasporic condition of homesickness and the longing for belonging' $(2000$, p. 195). But its intimations of a positive, liminal transmigrant status of 'in-betweeness' also serve to locate it within much broader social and existential parameters than simply being an 'issuebased' film about Asian migrants undergoing a painful rite of passage in adapting to the Australian nation-state.

\section{From a house in Hong Kong to a house in Australia}

Composed of narrative segments which shift between Hong Kong, Sydney and Munich, the film portrays from an interior, largely psychologically-based perspective, the varying degrees of difficulties experienced by three generations of the Chan family in adapting to and settling into their new habitats. It is a poignant and at times highly comical treatment of the family's predicament which explores, as Law has stated of a number of her films, multi-layered questions about 'the search for home' (Wang and Mitchell 2000, p. 6). Structured in a series of episodes, located in different habitats, each of which is introduced by 'Chinesestyle' printed titles in English and Chinese referring to different houses, the film relates the experiences of the different family members, and some episodes are narrated in voice-overs, or contain lengthy monologues by the various characters. The narrative shifts in location are linked by communication or conflicts between family members, and the titles signal these shifts: A House in Australia, A House in Germany, A House in Hong Kong, A House in China (the family's ancestral home which is rhetorically invoked as an imaginary origin), A House without a Tree, A House in Turmoil and A Big House (these three all in Sydney) and finally Mui Mui's House (the family's grand-daughter's future 
ancestral home in Germany). This narrative strategy of houses serves to direct the film towards a progression through different ideas of home, which have similar resonances for the Chan family to those enumerated in Mandy Thomas' focus on the primary importance of houses in her study of Vietnamese-Australians, Dreams in the Shadows. Thomas invokes Bachelard's characterization of the house as a place inscribed with memories and situated at the heart of 'our topography of our intimate being' (1969, p. xxxii). For her Vietnamese immigrant subjects in Australia, as for the Chans in Floating Life,

having a "home", both a metaphorical and physical space grounded in both domestic and local spheres, is a central concern ... not only (as) a space for sleeping and eating, but (it) may have religious significance because of ancestor worship ... the home remains the key site for the expression of a ... cultural aesthetic at the same time as it harbours the possibility of ownership.... A house may be the most essential form of concrete and manifest achievement ... and a symbol of transition to a state of being more permanently rooted. (1999, pp. 43,45,47,48)

For the Chans, as for some of the Vietnamese-Australian subjects Thomas recounts, the symbolic and geomantic importance of a tree, for example, becomes a major factor (1999, p. 42). In the film's opening moments, Mum (Cecilia Lee) and Pa (Edwin Pang), a retired tea merchant, are seen leaving Hong Kong with their teenage sons Yue (Toby Wong) and Chau (Toby Chan) to join their second daughter Bing (Annie Yip) in the rather barren and sterile-looking brick house she has bought in the leafy outer north-western suburbs of Sydney. (Law has indicated that the Sydney sequences were filmed in Castlereagh, a remote, affluent suburb near the Nepean river, between Penrith and Richmond, some sixty kilometres from Chinatown and the centre of Sydney (Wang and Mitchell 2000,p. 12). The tense, paranoid and rigidly disciplinarian Bing has lived alone in Sydney for three years, with only occasional visits from her 'astronaut' businessman husband Cheung (Bruce Poon), who has continued to work in Hong Kong, and who remains a shadowy, peripheral figure hovering helpfully but anonymously around the edges of some of the film's Sydney sequences. In his 'absent presence' and its isolating, alienating effect on Bing, Cheung embodies what Ong has described as ' $\mathrm{t}$ ] he astronaut as a trope of Chinese postmodern displacement ... and the toil it takes on an overly flexible family system' (1999, pp. 127-8). The uptight and repressive Bing attempts to school both her elderly parents and her younger brothers in what she regards as the rigours and perils of survival in the Australian suburbs, implementing what Kraicer has described as an 'iron regimen of total, cold-turkey assimilation to Western ways' (1998). 


\section{Tony Mitchell}

In a hilarious early sequence, the family discuss the dangers of life in Australia: the hole in the ozone layer which has caused numerous deaths from skin cancer, savage, murderous pit bull terriers, killer wasps and poisonous redback spiders. This episode is narrated wryly in English by the more 'adjusted' adolescent boys Yue and Chau, who, alluding mischievously to migrant detention camps, refer to Bing's house in Sydney as 'illegal custody, a concentration camp', and compare their initial experiences in Australia under Bing's authoritarian regime to a horror movie. From this house the family make their first symbolic foray into the suburban wilds of outer western Sydney, "our first and only great adventure' as the boys describe it. Armed with sunglasses, sunscreen and sun umbrellas, they venture timidly and tentatively down the deserted summer suburban street, only to scatter in panic in all directions when they are assailed by a tiny Jack Russell terrier. Pa then proceeds on to a ritual encounter with a kangaroo, squaring up with it in kung-fu-style pose, although the boys cast some doubt on the veracity of this somewhat mythical, symbolic event. This sequence of Pa 'boxing the 'roo' (kangaroo), which is filmed from a very high angle at one point to emphasize its mock-martial arts, ritual conflict overtones, becomes a metaphorical embodiment of the family's struggles to overcome their culture shock and adapt to their new environment. Audrey Yue has claimed that this sequence defines the Australian suburb as

a site/test for the migrant to pass (as in master) in order to take up cultural citizenship; in other words, in order for the migrant to pass as Australian, s/he has to be transformed into an ideal subject marked by stability, acceptance and visibility ... it connotes a cultural value that signifies Middle Australian ethnicity as ideal citizenry. The opening (sic) sequence of the film exposes the assimilationist politics of such an ethnicity by seizing on the iconic status of suburbia, reproducing and defamiliarizing it. $(2000$, p. 195$)$

But this reading of the suburb as a liminal test of Australian citizenship really only applies to one character in the film, the agoraphobic second daughter Bing, who suffers a nervous breakdown as a result of her fanatical desire to steer the Chan family into assimilationist Australian conformity. The Sydney suburb in Floating Life is a ghost town, as metaphorically empty and depopulated as the deserted Hong Kong cityscape in Law's earlier film about Hong Kong migration, Autumn Moon (1992, see Mitchell 2002). Floating Life charts the Chan family's struggles towards a sense of belonging in their isolated suburban home almost entirely on their own terms, (and they are economically self-sufficient enough to achieve this relatively easily in material terms) and there is little or no representation of conflicts with Australian norms of citizenship. Indeed, it is Bing who finally is seen to require 'transformation' by 
means of her mother's agency and assistance into traditional Chinese norms of 'cultural citizenship' after she suffers a nervous breakdown. Bing insists on speaking English at all times in the house, despite exhortations from her parents to 'speak Chinese', and expects the two boys to memorize their English dictionary, as well as making raids on their room and locking the television set in an upstairs bedroom. (After the boys retrieve the TV by means of a ladder to the bedroom window, they enjoy explaining the intricacies of an Australian soap opera to their mother. In a parallel sequence, $\mathrm{Pa}$ announces delightedly that he can pick up Mandarin-language news programmes on Radio Free China on his transistor radio, illustrating how media contact with family 'roots' exists alongside media readings of the adopted country).

Bing's concern with her parents' diet and the boys' moral education becomes fanatical, and she rants about how 'the house smells of AIDS' after she finds food and pornographic magazines in the boys' room, comically censuring her parents: 'You're here as migrants, not to enjoy yourselves'. (Elsewhere, as Stephen Teo (2001) has pointed out, she says 'You're here because you are fleeing your country', using the Chinese phrase zou nan, which designates refugees, and alludes to the wave of emigration from Hong Kong after the Tienanmen Square massacre in Beijing in 1989, when emigration figures rose markedly.) Bing represents the psychological dangers of over-assimilation, and appears to regard her migrant status as a necessary affliction; despite her moral condemnations of Australian values and her view of average Australians as decadent and lazy, she is dictatorial about succeeding in adapting to the ways of the new country. One of her aims is to save two million dollars in case the Australian government denies pensions to Asian-Australians. But the most drastic measure she takes in her regime of enforced assimilation is to forbid her parents to burn incense offerings to their ancestors in the house, because of the fire hazard this presents. It is this action which most tellingly illustrates her own deracinated, 'floating' status as a displaced migrant, for whom ancestors have no significance, and which eventually causes her to suffer a nervous breakdown. As Law has commented:

Bing tries to be totally Western, but actually she can't be because she isn't. She came on her own to Australia, a very different environment from Hong Kong. She is in the suburbs, and has to learn to live with nature, which is something she has never learned. She is afraid of people, and she is slowly building a wall around herself. When her parents and her siblings move over here, she tries to tell them that this is the way to live here. So she imprisons herself and her family. (in Berry 1996, p. 10)

As Shelly Kraicer has pointed out, Floating Life's three principal settings, Hong Kong, Sydney and Munich, are stylistically delineated as 


\section{Tony Mitchell}

subjectively very different physical spaces by Law, her Australian cinematographer Dion Beebe, and the film's production designer Yee Chung Man. This is done through the use of highly distinctive colour codes which are created by contrasting uses of film stocks, filters and levels of exposure. The different colour definitions provide a stylized, expressionistic view of each city which suggests the different family members' perceptions and impressions of their different environments. The Sydney sequences, shot in summer, are overexposed and bleached-out, conveying a harsh, stark brightness which suggests the prevalent glaring impact Australian light has on visitors from the northern hemisphere and elsewhere. These contrast markedly with the more 'neon-bright, detail packed and full colour spectrum' of the Hong Kong scenes, which as Kraicer suggests, convey in rich browns and darker colours 'the look, through the distorting mirror of anguished memory, of all the life left behind' (1996). The sequences in Germany, shot in winter, are more subdued and misty, with green pastel shades and dark blues predominant, reflecting the more sombre and subtle tones of European topography. So even in its differing cinematographic cartographies of place, the film offers aesthetic representations of the disorientation its characters enact in their respective displacements between Hong Kong, Australia and Germany.

\section{White Australia as a 'ghost town': a Sinocentric view of migration}

The film's first episode in Sydney, which is notable for its comical defamiliarization of Australian suburban spaces by presenting them through foreign eyes as threatening alien territory, also contains the film's only encounter between the Chan family and 'normative' AngloAustralians. In a sequence prefaced by Yue's ironic voice-over comment, 'I thought we had successfully merged ourselves into $\mathrm{Oz}$ ', a restless Yue throws a tennis shoe over the fence into the neighbour's garden, where a group of young Anglo-Australians are swimming in the backyard pool. The girl next door returns the shoe, introduces herself, invites the two boys over for a swim, and they strip off and climb over the fence. But this sequence, as one reviewer puts it, is then 'left dangling', confounding audience expectations that the film will 'depict the clash of cultures as the Chans struggle to acclimatize themselves into Australian society' (Fung 1998). Indeed, it is almost as if the sequence is inserted precisely to demonstrate the total absence of any exploration of interaction between the Chans and Anglo-Australians in the rest of the film, and possibly also reflects a survival strategy for the Chans. As Yue later explains to his sister Yen, in partial justification of Bing's repressive regime, "we have to be independent, especially as we are Asian here'. This situates the family in the transnational margins and on the edge of the conventional Australian mainstream, and suggests these marginal spaces can contain what 
hooks has called 'the site of radical possibility, a space of resistance' (1990, p. 149). This 'Asian independence' may be a vital space of selfpreservation given Ghassan Hage's definition of the Australian mainstream as 'a space structured around a White culture, where Aboriginal people and non-White "ethnics" are merely national objects to be moved or removed according to a White national will ... whether in the form of a White multiculturalism or in the form of a White racism' $(1998$, p. 18). As Dominic Pettman has observed, Floating Life's perspective rather neatly reverses this normative white symbolic order:

The film's depiction of actual Australians (whatever such a fraught term may mean) is fleeting and peripheral, as if they themselves are ghostly apparitions haunting the fringes of the landscape. The overall effect is that the 'natives' themselves become spectral and surreal, whereas the newly arrived immigrants are vivid and fully materialised in this new place. $(2000$, p. 76$)$

The deserted outer Sydney suburbs are a ghost town through which the Chan family wanders as the protagonists of their own isolated psychological drama of adaptation to their new habitat. In refusing to concern themselves with expected confrontations with normative Australian society, Law and Fong risk provoking the accusations of ethnic and cultural separatism which are frequently levelled against Asian migrant groups by representatives of the Anglo-Australian mainstream. On the other hand, the film's resolutely mono-ethnic Chinese perspective offers a complete reversal of the tendencies of previous films and other forms of fictional narrative about non-Anglo-Australian immigrants to portray them as victims of a repressive, intolerant and uncomprehending Anglo-Australian mainstream. In their exclusive, but always compassionate and often poetic portrayal of the Chan family's predicaments as Australian settlers from an interior, psychological perspective they succeed in evoking audience empathy without needing the added emotive ammunition of portraying conflicts with representatives of the Anglo-Australian nation-state.

Nonetheless, the film has been mobilized as a major representation of the predicament of non-Anglo migrants in Australia. Arthouse film presenter David Stratton, introducing Floating Life as an SBS Film of the Week in 1998 as part of a season of programmes entitled 'Aspects of Racism', commented on the 'delicacy, humour and insight' of its portrayal of 'new Australians' - that quaint, 1950s' term for non-AngloAustralian immigrants. (The only incidence of racism that occurs in the film is when Yen, the second daughter, silently confronts a neo-Nazi skinhead in a Munich shopping mall.) In a review of the film in the Australian newspaper, Stratton pointed out that, in contrast to previous Australian films about migrants like Michael Powell's adaptation of 


\section{Tony Mitchell}

Nino Culotta's They're a Weird Mob (1966) and Sophia Turkiewizcz's Silver City (1985) 'which dealt with the gradual integration of Italian and Polish migrants respectively', Law's film shows virtually no interaction between the Chans and Anglo-Australians. He suggested diplomatically that 'this lack of contact isn't a comment either on the racism of Australians or the clannishness of Chinese migrants; it's just that Law is more interested in how such a dislocating move affects the members of one particular family' (1998). But as Roxburgh has noted, with reference to the Chinese-Australian writers Sang Ye and Ouyang Yu, Floating Life could be read as being consistent with a tendency in Chinese-Australian literary and popular discourse to either ignore or present 'unflattering images' of Anglo-Australians, sometimes even using terms like yang guizi (foreign devils). Roxburgh theorizes this as follows: 'Through this absence of the Australian Self, Law has constructed the members of the Chan family as simultaneously Self and Other, or "Self-Whole" (1997, p. 4). But it is more likely that this 'Australian Self' simply does not figure at all in Floating Life, even as an absence, and to claim that it does is a presumption brought to it by overly-nationalistic readings of the film as 'Australian'. On the contrary, the thoughts, feelings and actions of the film's Hong-Kong-Chinese protagonists, including Bing, could be read as almost entirely and reflexively 'Sinocentric', and justified as such. This is consistent with what Ouyan Yu has described as the "invisibility" of normative AngloAustralians in contemporary writing by Chinese in Australia' (in Barrowclough 1996, p. 47), and with Law's own comments about the absence of interaction by the Chan family with Anglo-Australians in the film:

I think it's because the approach is not a naturalistic approach. What we want to deal with is the inner world of the immigrants, what it's likc to come, to be cut off from your roots, and try to build and to plant new roots in a new soil. That actually is more important, that area is what we should focus on, instead of showing how they relate to others, because you relate to others in an external way, but that doesn't show how you can relate really internally with your new home. In order to be able to do that, you have to be able to find your own feet on the ground. If you can't do that, there is no way you can connect ... those superficial things of having a relationship ... I think that actually doesn't help at all. We need to say, "Look, these are new people, they need to find their own bearings". Like Mum, finding her way home, it's also her real bearings. (Wang and Mitchell 2000, p. 12)

Issues related to 'bearings' are dramatized in the poignant closing sequence of the 'House in Australia' episode, in which Mum and $\mathrm{Pa}$ wait at a remote, desolate suburban bus stop to go to their English lesson in 
the city. Ma suggests going to Chinatown to buy some incense to burn as the next day is Ching Ming, the Day of the Ancestors. After they miss the bus, since Mum has forgotten her glasses and Pa thinks the one that arrives is the wrong bus, Mum tearfully rejects the incense suggestion, since Bing will not allow them to burn incense in the house anyway, and they are too far away from their ancestors for their incense to reach them. A conciliatory Pa then quotes his own father - who, we later learn, fled on foot from mainland China to Hong Kong in 1949 - expressing the need to 'follow the customs of the new village'. This scene is underscored by plangent Chinese-style music (played by the Chinese Opera Arts Orchestra and composed by Iranian-Australian musician Davood A. Tabrizi) which, in keeping with Eng's reading of the film (1999a), establishes a powerful tone of melancholy and loss as the couple acknowledge their inability to carry out their duties of filial piety (Teo 2001). But this is tempered by the pragmatism of Pa's comment, which signals his later construction of a Chinese hereditary habitus on Australian soil. Here as elsewhere in the film, the music reinforces atmospherically a subjective, interior focus, which rather than examining the social aspects of immigration, displacement and adaptation to a new environment, focuses in a stylized, subjective and often metaphorical way on the psychological and cultural effects.

\section{Floating Life as a transnational film}

Despite being technically (in terms of financing and production) the first Australian film to be shot predominantly in languages other than English, and the first Australian film to be nominated for a US Academy of Motion Picture Arts \& Sciences award in the Best Foreign Language Film category (in 1997), Floating Life itself occupies a curiously anomalous and displaced position in Australian national and international cinema. An 'arthouse' film lauded by some Australian critics as an important landmark in AsianAustralian cultural representation and identity politics and even seen as 'a narrative of one of a myriad of Australian identities' in which Self and Other become somewhat mystically unified (Roxburgh 1997, p. 6), it was nominated for three Australian Film Institute Awards (best director for Law, best screenplay for Law and her husband Eddie Fong and best supporting actress for former veejay and TV announcer Annette Shun Wah). But it was seen by very few audiences in Australia, Asian or otherwise - it ran to largely empty cinemas for little more than two weeks in the main cities, although it was acclaimed at the 1996 Sydney and Melbourne film festivals, and has been subsequently screened four times on the Australian multicultural TV network SBS. (SBS included a clip from the film in the montage of its output assembled to advertise the channel's 2000 Global Outstanding Achievement Award, an indication of SBS's association with the film as a co-producer, and the film's own global orientation, 


\section{Tony Mitchell}

as well as signalling the film as an ideal example of the local production values and content of the channel).

In contrast to its muted response in Australia, the film was highly praised at Western international film festivals such as Locarno - where it won the Silver Leopard and three other smaller awards - and Toronto. Chinese responses have been more negative: the Golden House Film Festival Committee in Taiwan, on the other hand, suggested 'it is well worth applying reverse logic when responding to the direct way Clara Law's Floating Life confronts its viewers with its overstated sadness and homesickness.' Hu Xing Chi also commented on the 'multiple marginalized' status of the film's protagonists, but noted how Hong Kong migrant friends saw the film's portrayal of their struggles as 'a betrayal of the migrant experience' and as 'giving the West a bad impression' (1997, p. 45). The film was also characterized as 'a good example to study as a Hong Kong national film which explores the Hong Kong experience' of migration by another Taiwanese film critic, Li Ya Mei (1997), contesting claims for the film's Australian identity. These contrasting readings of the film outside Australia and the Anglophonic world suggest it may have more appeal to Western viewers who are able to sympathize with the transmigrational predicament of the film's Chinese characters from a distance than to Chinese audiences who may find its emphasis on homesickness excessive. At the 1997 Philadelphia Festival of World Cinema, it was lauded as 'the first Australian film about the Chinese diaspora, and the first to deal meaningfully with the immigrant experiences of recent arrivals from Hong Kong'. As Law and Fong have acknowledged, removing themselves from the commercial pressures of film making in Hong Kong and translocating to outer-suburban Melbourne was a result of a discovery that 'our audience is not just Hong Kong - it's a select group, but it's worldwide' (in Dannen and Long, 1997, p. 109). Consequently Floating Life's status as a significant contribution to Australian national cinema is a matter of contestation, just as its identity as a Hong Kong film is also disputable. Law and Fong's own position as emigré film makers is based on a strong rejection of what they regard as the dominant commercial, entertainment ethos of Hong Kong cinema and its scant regard for a more reflective arthouse cinema. As Fong put it:

I think in Australia we get more support, and more people can accept you as an artist, being a film maker, but in Hong Kong people can't accept you as an artist if you're a film maker. You can be an entertainer, you can be a businessman, you can be anything, but not an artist, they don't accept you as an artist. (in Wang and Mitchell 2000, p. 7)

This places them in a liminal position in which they are bound by the borders of neither Hong Kong cinema nor Australia cinema, but can 
benefit from Australian government funding and distribution while retaining their cosmopolitan identities and international reputations as Hong Kong film makers. This is a different kind of transnationality and flexible citizenship from that which the Chan family is striving to achieve in transplanting their Chinese heritage into an Australian habitat. But as Law has stated, their own transcultural identity is virtually an attempt to erase national borders altogether:

It actually has no meaning for me, being an Australian, or Hong Kong, or Chinese director. I'm still what I am: I'm not totally Eastern or totally Western, you know, an embodiment of cultures. It's more like dealing with a different system here, and how to overcome the difficulties. That's more my concern than the fact that I'm Australian now, and so have to behave like an Australian or think like an Australian. (Ibid., p. 15)

This statement offers an interesting variation on Ong's account of negotiating flexible citizenship from a Hong Kong perspective: 'From the perspective of immigrants such as well-heeled Hong Kongers, however, citizenship becomes an issue of handling the diverse rules, or "governmentality", of host societies where they may be economically correct in terms of human capital, but culturally incorrect in terms of ethnicity' (1999, pp. 112-13). The differences between the struggles of the protagonists of Floating Life, who 'deal with a different system' and 'overcome difficulties' in Australia with considerable duress, suffering and loss, and the fluidly transnational, liminal, and cosmopolitan position assumed by its screenwriter and director suggests interesting class contrasts which Mar's research also reveals.

Mar shows that from the mid-1980s to 1992, immigrants to Australia from Hong Kong formed the largest national group, peaking at 16,656 in 1991-92 (1998, p. 58), but that rather than fitting "'modernist" images of the migrant trajectory' from a less to a more developed country, most of these immigrants, like the Chan family in Floating Life, came to Australia as an 'insurance policy' (p. 72) against the uncertainties of the 1997 Hong Kong handover to China. (Although rather than an example of migration of the affluent, this could be seen as a riposte to Thatcher's British nationality bill, which was conceived as 'an "insurance policy" to keep would-be Chinese citizens in Hong Kong up to and beyond 1997' (Ong 1999, p. 122)). This postmodern model of migration reaches its most developed form in the 'astronaut' (taai hung $y a n$ ), the (usually male) 'wealthy trans-migrant' who maintains business activities in both Hong Kong and Australia (p. 59) but who nonetheless shares a sense of uncertainty of the situation, the provisionality of their settlement, and the transnational range of their perspectives' with their less wealthy 'settler' counterparts (p. 59). Mar 


\section{Tony Mitchell}

chronicles his interviewees' prevalent perceptions of spacious Sydney suburbs as non-urban, isolating, spread-out, quiet, boring, secure, free, empty, white and slow, in neat binary contrast to the small, dense, noisy, dynamic, fast, stimulating, dangerous, uncertain and dynamic Chinese urban cosmopolitanism of Hong Kong (p. 62), which occupies the major part of his survey. In this respect they are consistent with the characters in Floating Life. He also finds an example of a female Chinese immigrant who, like Bing, experiences 'the trauma of domestic spaces that are rendered uncanny and dangerous because they are not truly at home' (p. 69), and that a large proportion of Hong Kong migrants who come to Australia 'return to Hong Kong for long periods if not permanently' (p. 65), which places the Chan family in a minority in terms of their attempts to put down permanent roots in Australia and transplant their Chinese hereditary customs there. In contrast, Law and Fong's position becomes more aligned with that of the astronaut, 'surf[ing] ... global flows at will' (p. 70) around the international film festival circuit, although they maintain a permanent base as 'settlers' in Melbourne. As Mar notes: 'there are great differences in potential to take advantage of the globalising circuits we are told are there for us to capitalise on' (p. 70), but Hong Kong immigrants in Australia who "'settle well" find their place and value its attributes. The quiet is no longer too quiet' (p. 66). Nonetheless, given the continuing uncertainty of the political and economic climate in Hong Kong since the handover, the predicament of most Hong Kong immigrants in Australia appears to be one of transnational flexibility, and both 'astronauts' and 'settlers' may 'maintain a practice of moving between Hong Kong and Australia over a long period of time'. This is consistent with James Clifford's notion of home as 'a series of locations and encounters, travel within diverse, but limited spaces' (cited in Kaplan (1996, p. 168). Hence, rather than reaching a climax in 1997, transnationality for Hong Kong Chinese migrants appears to be a continuing state, a perpetuation of the 'culture of disappearance' invoked by Abbas (1997, p. 7).

Floating Life itself seems to have become a transnational entity, occupying a 'floating', displaced geopolitical region somewhere between Hong Kong, Australia and the international arthouse cinema circuit. As Pettman has noted, the film is

symptomatic of [an] uncanny and ubiquitous cross-cultural liminality. An Australian film critic [David Stratton] calls it "one of the most beautiful Australian films of the past few years", while the Hong Kong industry considers it merely an expatriate extension of their industry. $(2000$, p. 75$)$

On the one hand, it is an Australian-produced film with a cast consisting almost entirely of non-professional Chinese-Australian actors (including 
the executive director of the museum of Chinese Australian History, who plays $\mathrm{Pa}$ ), with a promotional flyer proudly proclaiming that 'no Australian film has told this story before'. As such, in the company of films by diasporic Chinese-Australian directors such as Pauline Chan, Teck Tan and Tony Ayres, as well as Solrun Hoaas' Aya (1990), which deals with the experiences of a Japanese war bride in Australia in the 1950s, it offers some refutation of Jon Stratton's statement, made in 1998, that 'with the problematic exception of Romper Stomper, there are still no films that present Vietnamese, Chinese, Japanese, Timorese, and so forth, as participants in Australia's everyday multiculturalism' (1998, p. 168). The sense of a continuing series of specific Asian migrant groups with Australian migrant stories to be told in the 'and so forth' here contests both the 'danger of being swamped by Asians' (in Woodford 1996) famously referred to in 1996 by Pauline Hanson, and the tactics of the pathetically deluded skinheads who wage war against Vietnamese street gangs in Melbourne in Geoffrey Wright's film Romper Stomper (1992) which also 'reanimate(s) White Australia's menacing "Asian" sublime' - to use Meaghan Morris's expression (1998, p. 255). But the homogenizing and assimilationist tendencies of what Hage has referred to as 'white cosmo-multiculturalism' (1998, p. 202) are also exposed in the expectations placed on an Australian national cinema to incorporate, assimilate and contain 'Asian-Australian' films about Asian subjects within its 'everyday multiculturalism'.

Nonetheless, Felicity Collins has located Floating Life evocatively within a shared feminist, 'othering' discourse of 'bringing the ancestors home' on the margins of a traditionally white, masculine Australian landscape alongside Aboriginal Australian film maker Rachel Perkins' study of conflict among three sisters, Radiance (1998) and Margot Nash's contrast of Anglo-Australian and Aboriginal neighbours in Vacant Possession (1995). This suggests all three films may, like the Chan family, operate within hooks' notion of a 'site of radical possibility, a space of resistance' (op, cit.). Ilowever, Collins' suggestion that the final scene of Floating Life, in which the grand-daughter Mui Mui expresses her future vision of a united family in Germany, offers a 'genealogical resolution to a transnational and diasporic history' $(1999$, p. 114) sets it very much apart from Radiance and Vacant Possession, as does the final rehabilitation by Mrs, Chan of her second daughter Bing, which Collins describes as 'an emotional sequence unprecedented in Australian cinema' and which contributes to 'a unique image of the mother in Australian cinema' (1999, pp. 112,115). Audrey Yue has perhaps more usefully situated Law with Chinese-Australian director Tony Ayres in what she has referred to as a 'second phase' of Asian film making in Australia, after the films of Pauline Chan and Teck Tan, where 'post-ethnicity interrogates Australia's Euro-centric postcoloniality', and 'reflects the rise and fall of Asia, inflects the Asian turn in Australia, and articulates a discourse of transnational Asian mobility' (2000, p. 190). 


\section{Tony Mitchell}

Floating Life could also be read as a refusal to engage with many of the basic assumptions of 'everyday multiculturalism', and as relating more to the consistently transnational focus of other films in Law's oeuvre, which deal with Japanese, Chinese and Hong Kong migrants in Canada, the USA, China and Hong Kong as well as Australia. This makes it crosscultural in a much broader sense than simply 'Asian-Australian'; as Law has stated, 'What I've been setting out to do is to speak across cultures, so that culture doesn't become a handicap but something that enriches' (in Giese, 1997, p. 290). The Hong Kong-Chinese-Australian protagonists Floating Life focuses on almost exclusively might even be situated within the more defiant kind of hyphenated identity discourse that Hage appropriates from one of the South Asian British migrant characters in Udayan Prasad's film Brothers in Trouble: 'Many Asian migrants who have arrived here in the past twenty years ... have accumulated enough national belonging to tell even those who approach them with an unnecessary "You're welcome" to "Mind their own bloody bastard business"" (1998, p. 227). In any case, it is a film which situates Australia within a Hong Kong-Chinese migrant diasporic framework, rather than the other way around, exposing the narrow provincialism of traditional notions of the Australian nation-state and embodying what Morris has described as "the idea of enmeshing Australia culturally as well as economically in "an Asia-Pacific world"' (1998, p. 240). This echoes a statement made by Australian Prime Minister Bob Hawke in 1984 about 'enmeshing' Australia's economy in the Asia Pacific Region, which signalled a shift in perceptions of Australian identity since the early 1980s away from an orientation towards Europe to a stronger sense of identification with Australia's geographical location in the Asia Pacific region (see Frost 1994 for a discussion of the complexities of this position). Under the current Howard government, however, fuelled by phobias about asylum seekers and the Asian economic crisis, this process has been substantially rolled back into a 1950s-style neo-colonialist Anglocentrism.

Instead of telling an Australian 'migrant' story, then, Floating Life situates its 'floating' characters in the context of Hong Kong diasporic migration to the USA, Australia and Canada as well as Australia, and situates Australia, and Australian dilemmas of identity, firmly within an Asia Pacific regional context.

\section{Feng shui and family harmony}

Feng shui which Ong defines succinctly as 'propitious placement determined by geomancy' (1999, p. 87) is particularly important to Hong Kongers who move from urban congestion to more open spaces; as Ong states, they are "exquisitely concerned with the importance of location ... the hidden value of [which] is as a confluence of good fortune and social power ' (p. 2). It is used in Floating Life as an important indicator of the 
Hong Kong migrant's process of adaptation to a new environment. The second major sequence in the film, A House in Germany, focuses on the dilemmas of the first daughter Yen, who migrated to Germany ten years prior to the rest of her family's translocation to Australia. Yen lives in Munich with her German husband and daughter Mui Mui, whom she is trying to encourage to speak Cantonese. Her efforts are frustrated by her husband, who has told Mui Mui that Hong Kong Cantonese is not 'real Chinese'. This adds to Yen's own sense of identity crisis, which is compounded by the fact that she herself doesn't speak Mandarin, and her anxiety about Hong Kong becoming a Special Administrative Region of Mainland China. Yen's sense of displacement and disorientation in Germany is expressed metaphorically through her obsession with the bad feng shui of the new apartment they have moved into, and is physically embodied in the constant itching which she suffers from. This culminates in a poignant, tearful monologue delivered in German in bed to her husband, who tries to insist she is German, in which she says ' $I$ don't know where my home is ... I don't even know if I should even think of myself as Chinese ... I speak German with an accent ... I live in Germany but I'm not really German ... Where is my home? I only know that my roots are with my parents.' She decides to visit her parents in Australia ('Is the feng shui better in Australia than here?' her husband asks) and we next see her in Hong Kong with her brother Gar Wai, who is waiting for his visa to join the rest of his family in Australia.

The film's focus then shifts to Gar Wai, (Anthony Wong) a hedonistic stockbroker and sexual experimenter who is symbolically obsessed with his own ejaculations and the death of his semen. While waiting to migrate to Australia with his girlfriend Sandy, he casually befriends Apple, a transient Hong Kong-Chinese girl on holiday from Vancouver who is staying at his house, and gets her pregnant amid scenes of hysterical laughter. He then insists on keeping the foetus when she has an abortion, and deludes himself that it is still alive and throbbing. The dead foetus becomes a metaphor for Gar Wai's own identity crisis, sense of mortality and lack of connection with his family lineage, and he buries it in the garden of his apartment a rather grisly ritualized ceremony. This ceremony is dovetailed with Gar Wai's removal of his grandfather's bones from the local cemetery, where they have been displaced due to lack of space. Teo interprets his morbid preoccupation with the aborted foetus as a variation of the themes of filial piety, and a reaffirmation of the 'tie of kinship that he in his own way has established with Hong Kong, his home' which he commemorates symbolically by burying the foetus. (2001). His voice-over monologues link these themes to the anxieties of the 1997 Hong Kong handover, which he expresses repeatedly.

Back in Sydney, the family go on an outing to Centennial Park to commemorate Yen's arrival. Yen and Bing later come into conflict about family responsibilities, with Bing arguing mainly in English, Yen in 


\section{Tony Mitchell}

Cantonese, as befits the two sisters' linguistic expression of their own differently hyphenated identities, anxieties and insecurities. As Law has described them:

Bing and Yen move away from Hong Kong knowing that it is not their place. Especially for Bing, the feeling is that you've been abandoned. I think this is what most Hong Kong people feel; that we're neither welcomed by the Chinese nor the British, and we don't trust either of them. So you're on your own, and you can never trust any of these people.... (in Berry 1996, pp. 10-11)

The two sisters' ongoing argument is interrupted by the need to look for $\mathrm{Pa}$, who has disappeared, having met up with an old friend from Hong Kong who tells him about visiting his ancestral home in China, and shows him a photo of it. Pa realizes he will probably never see his own ancestral home, and talks of friends who have immigrated to Toronto and Seattle and who no longer even send him Christmas cards. His disorientation and sense of isolation from both China and Hong Kong is poignantly expressed as a generic condition among his generation.

We then shift into Bing's 'backstory' - her hysterical distress at seeing a rat in her house, an uneasy encounter with a kangaroo, and her lonely struggle to make do in Sydney and secure 'a 100 per cent clean, tidy and secure house'. She refuses an offer of a drink from her office workmates, and eats alone at Chinese New Year at a single table in a Chinese noodle shop, whose waiter she sends away when he offers to cook a candlelit dinner for her at home. This establishes the loneliness and sacrifices she has endured for the good of her family, in her 'second house without a tree', which symbolizes the barrenness of her existence, in a sequence which serves to generate some degree of sympathy and compassion for her.

But unable to endure Bing's regime of adaptation to the new country, Mum and Pa buy a new house, and an outraged Bing offers to be the two younger boys' guardian. Chau accepts, but not Yue, which causes an hysterical outburst from Bing, and conflict with Gar Wai, who has arrived from Hong Kong. The three brothers are eventually reunited on a beach, drinking beer in true 'Aussie' style and ogling an Australian girl ('too tall', a complaint the two younger boys have expressed earlier in a comical scene with a Chinese-Australian doctor who suggests lengthening their limbs), while Gar Wai continues to lament his dead semen. The family, with the exception of Bing and Yen (whose absence indicates she has returned to Germany), are reunited in the new house, causing Bing, alone in her house, to sink into a catatonic depression. Ma visits Bing a number of times, taming the irascible neighbourhood dog in the process, and eventually successfully ordering it to sit, a symbolic ritual encounter which charts her gradual acclimatization to the new country. After Bing 
fails to respond to her offer of ginseng soup, Ma lights incense and addresses the family ancestors in a moving, tearful prayer, apologizing for the distance which separates them and for their lack of filial respect: 'After all these years of not having a homeland, now we have achieved our goal ... the whole family is together in Australia, this paradise on earth. Why can't we have any joy? Why can't we put down our burden, and plant our roots in this soil?' Bing emerges from her bedroom during this prayer, and sits in silence crying on the stairs, assisting passively in this healing ancestral ritual which does not solve the family's dilemma, but achieves a temporary, expiatory peace. This peace is complemented by $\mathrm{Pa}$ in the garden of the new family home, organizing its feng shui, planning a lotus pond similar to that of his ancestral home, and a greenhouse in which to grow quality tea leaves, reviving the professional skills which he has had to give up since leaving Hong Kong.

The film's final two brief sequences establish a fragile sense of harmony and completion. Ma coaxes Bing out of her house and on to the street after a month's efforts (and the boys' narration adds that Bing even becomes pregnant eventually), and Yen's daughter Mui Mui describes, in a mixture of Cantonese and German, her ancestral home, a very European-looking house in a winter landscape, which her (paternal) grandmother has promised her, and which belonged to her grandmother's grandfather. It is notable that this final sense of compromised rootedness and partial resolution of the family's conflicts and displacements is achieved almost entirely through the efforts of Mum and $\mathrm{Pa}$, who, unlike frequent portrayals in Australian and other cinema of older migrants as the most severely displaced victims, demonstrate a pro-active engagement with their new environment which is stronger than that of their children. As Law has commented, this is because

... they have more of a bearing. They're solidly grounded in their own culture; they don't feel that this new culture has to be part of their culture. They accept that this is their new home and they have to learn, and that there are many things to adapt to, and yet at the same time they're totally grounded in their own culture. They have their ancestors, they're connected to their past, which gives them strength. But Bing is not connected; to her ancestry doesn't mean a thing. She has to learn (Wang and Mitchell 2000, p. 13).

It is within primarily Confucian notions of family harmony and filial piety and by opening lines of communication with the family ancestors that the Chan family achieve a relative degree of harmony and integration in their new Australian environment - reconciling their Chinese heritage, their troubled Hong Kong homeland identities and their Australian and German residence. Law has invoked a 'new Confucianism', in the sense of 'reinterpreting what through the years has 


\section{Tony Mitchell}

become mispractised and stale' (in Giese 1997, p. 164) and reviving traditional beliefs and family unity, as the most important force for the survival of Chinese migrant families. Ong, on the other hand, has identified a 'Confucian cultural triumphalism' which derives from a narrow, ideological PRC-based Chinese essentialism and has paralelled Chinese transnationalism in Southeast Asia, reviving "premodern forms of child, gender, and class oppression, as well as strengthened authoritarian regimes in Asia' (1999, p. 135). Audrey Yue has also commented that the 'Asian visibility' which films such as Floating Life have brought about in Australia 'paradoxically also signifies the rise of a modern Asian culture materialized through the values of capitalist middle-classness and neoConfucian patriarchy' $(2000$, p. 199). But it is arguable that the neoConfucianism Law invokes, and the yearning for tradition to regulate disfunctional family conflict and turmoil which the gentle and caring Mum and Pa embody in Floating Life is closer to what Thomas has defined as

the emphasis that Confucianism places on hierarchical family relations, filial piety, ancestor worship and well-defined roles in the family ... where the aged hold positions of power or are close to that power, where they are considered more adept at problem-solving, closer to the ancestors, and the upholders of family values. $(1999$, p. 198)

It is also difficult to see the strong female characters who dominate Floating Life as embodiments of patriarchy - indeed, Collins' reading of the film in terms of an enabling feminist maternal imaginary suggests the opposite. The final sequences of Floating Life embody a traditional Confucian harmony, despite the lack of complete family unity, which is close to Ong's paradoxical claim that 'flexible citizenship is a result of familial strategies of regulation' (1999, pp. 117-118). The last sequence, showing Mui Mui's house (and we see a child, presumably Mui Mui's, running up the garden path), projects the Chans' diasporic transmigration into the future, suggesting a sense of family integration more secure than their present residence in Australia.

\section{Internationalizing local knowledges}

Regarded in the limited context of Australian national cinema, Floating Life offers substantial refutation and reversal of Hage's diagnosis of mainstream 'multicultural' films like Strictly Ballroom (1992) and Death in Brunswick (1991) 'whose very structure is based on an opposition between an archaic, restricting Anglo-Australian culture and a living, promising, White cosmo-multiculturalism' in which 'the "ethnic element" is included and even welcomed into the world of the White multiculturalist ... but only for as long as it knows and keeps to 
its place' $(1998$, p. 202). Nonetheless, it continues to occupy a subordinate and subaltern position in Australian national cinema canons similar to that of films like Vietnamese-Australian director Pauline Chan's Traps (1993) and Aboriginal director Tracey Moffat's Night Cries (1987) which, as Morris has pointed out,

are often relegated by critics to the worthy periphery of national cinema: "independent", "feminist" or "multicultural" films. Certainly they mark the limits of the national cinema project classically understood: centred on the experience of women and children shuttling or shuttled around the world, they internationalise local knowledges of national tensions rather than helping to build a cohesive "population" in one place. $(1998$, p. 256$)$

In Floating Life, Appadurai's ethnoscapes and mediascapes cohere with ideoscapes (1990, pp. 6-7) in a film about Asian migration to Australia in which the global dispersal of transnationality is the central focus, and Australia the incidental, or peripheral locus of this migration process. This sense of a globalized displacement emphasizes that while Floating Life can neither be exclusively pigeonholed as an Australian film, nor simply be marked off as a Hong Kong or a 'Chinese diasporic' film. Law has suggested that ultimately it reflects her own situation as a traveller as much as the predicament of her transmigrant characters:

The movie is more an extension of all my travel experiences ... everywhere I went, the question remained the same: is my identity about where I'm from or where I might some day find I belong? ... I didn't make Floating Life to only come across to the Chinese ... It's addressed to the state of our human condition nowadays. Alienation and dislocation are rampant. We're all so self-sufficient - we've got our little home office, our email, our video games, our online friends, but we're cut off from any real human contact. We're like professional tourists moving through life, unable to register our own experiences unless we see photos of them, or watch them on videotape. (in Files, 1997)

The doubly hyphenated Chinese-Hong-Kong-Australian identities that the film explores, alongside its Chinese-Hong-Kong-German characters, confront a more deep-rooted sense of alienation and displacement than that merely involved in the process of becoming 'new Australians'. This ranges from the tangential 'astronaut' Cheung to the bicultural, bilingual Mui Mui to the neurotic, excessively Westernized settler Bing to Mum and Pa's final establishment of a conduit to their Chinese ancestors which enables them to find a sense of belonging in their new home. 


\section{Tony Mitchell}

In a discussion of Law and Fong's 1990 film Farewell China, a harrowing pre-Tiananmen Square study of a mainland Chinese couple's degrading experiences as migrants in New York (see Mitchell 2001), Sheldon Lu suggests that recent Hong Kong cinema expresses a new post-Cold War form of cultural production in Hong Kong and China which has responded to 'transnational social and economic formations' in bringing about a change 'from the discourse, ideology, and geopolitics of the nation-state to a more flexible notion of citizenship among the Chinese'. While Farewell China, he argues, still projects the nation-state as 'the emotional basis for a sense of identity and selfhood', more recent films like Peter Chan's Comrades: Almost a Love Story (1997), about two mainland Chinese characters who transmigrate to Hong Kong and then New York with considerable upward mobility, express a more 'postmodern, diasporic condition' of 'ethnic Chinese scattered around the globe' and 'a transnational, flexible, diasporic citizenship ... without the blessing of a secure national affiliation' $(2000$, p. 285). The ultimately positive process through which the Chan family settle in Australia in Floating Life could be read as a similarly transnational expression of a 'postmodern diasporic condition' which is independent of any ties to nation-states, whether they be Chinese or Australian. While this fluidity and flexibility is clearly reflected in Law's description of her own independent, mobile, transnational identity as an international film maker, Floating Life deals with the Chan family's problems of adjustment in relation to their survival as a displaced ethnic Chinese family unit. Their process of settlement in Australia is eventually achieved symbolically through a metaphorical, ritual conflict in which the Chan parents befriend the neighbourhood dog, box the 'roo, and the family 'successfully merge(s) into $\mathrm{O} z$ '

\section{References}

ABBAS, ACKBAR 1997 Hong Kong: Culture and the Politics of Disappearance, Minneapolis: University of Minnesota Press

APPADURAI, ARJUN 1998 'Full Attachment', Public Culture, vol. 10, no. 2 Winter, pp. 417-50

- 1990 'Disjuncture and difference in the global cultural economy', Public Culture, vol. 2, no. 1, Spring, pp. 1-20

BACHELARD, GASTON 1969 The Poetics of Space, Boston, MA: Beacon Press

BARROWCLOUGH, NIKKI 1996 'Through Chinese eyes: new visions of Australia from Tiananmen Square exiles', Sydney Morning Herald Good Weekend, 13 July 1996, p. 48 BERRY, CHRIS 1996 'Floating Life', Cinema Papers no. 110, June, 10-11

CUNNINGHAM, STUART, SINCLAIR, JOHN et al. (eds) 2000 Floating Lives: The Media and Asian Diasporas, University of Queensland Press

COLLINS, FELICITY 1999 'Bringing the ancestors home: dislocating white masculinity in Floating Life, Radiance and Vacant Possession', in Deb Verhoeven (ed.), Twin Pceks: Australian and New Zealand Feature Films, Melbourne: Damned Publishing, 107-116

DANNEN, FREDERIC and LONG, BARRY 1997 Hong Kong Babylon: An Insider's Guide to the Hollywood of the East, London: Faber and Faber 
DREHER, TANIA 2000 'Mapping media power', CommunalPlural, vol. 8, no. 2, October, 257-64

ENG, DAVID 1999a 'Melancholia/postcoloniality: loss in The Floating Life (sic)', Qui Parle, vol. 11, no. 2, pp. 137-50, 161-64

_ 1999b 'Melancholia in the late twentieth century', Signs, vol. 25, no. 4, Summer, pp. $127-34$

FILES, GEMMA 1997 Review of Floating Life, www.eye.net/eye/issue_06.26.97/film/ files.html

FROST, STEPHEN 1994 'Broinowski versus Passmore: a dialogue of our times', Continutum, vol. 8, no. 2, pp. 20-49

FUNG, ALEX 1998 Review of Floating Life, www.ncf.carleton.ca

GIESE, DIANA 1997 Astronauts, Lost Souls and Dragons: Voices of Today's Chinese Australians in Conversation with Diana Giese, University of Queensland Press

HAGE, GHASSAN 1998 White Nation: Fantasies of White Supremacy in a Multicultural Society, Sydney: Pluto Press

hooks, bell 1990 'Choosing the margin as a space of radical openness', in Yearning: Race, Gender and Cultural Politics. Boston, MA: South End Press, pp. 145-53

HU XING CHI 1997 'From Floating Life to Comrades: Almost a Love Story: Here or There. Home and Homesickness', Film Appreciation Journal (Taipei), vol. 6, no. 45 (trans. Haiyan Wang)

KAPLAN, CAREN 1996 Questions of Travel: Postmodern Discourses of Displacement, London: Duke University Press

KRAICER, SHELLY $1998^{\circ}$ Review of Floating Life at the 1996 Toronto International Film Festival", www.geocities.com/Tokyo/5170/floating.html

LAW, CLARA 1996 'Director's Statement', Pardo Film Festival (http://www.pardo.ch/ 1996/festival96/floatingreg.html)

LI YA MEI 1997 Review of Floating Life, in Imagekeeper (Taipei) no. 1 (trans. Haiyan Wang)

LU, SHELDON 2000 'Filming Diaspora and Identity: Hong Kong and 1997', in Poshek Fu and David Desser (eds), The Cinema of Hong Kong: History, Arts, Identity, Cambridge University Press, 273-88

MAR, PHILLIP 1998 'Just the place is different: comparisons of place and settlement practices of some Hong Kong migrants in Sydney", The Australian Journal of Anthropology, vol. 9 , no. 1 , pp. 58-73

MITCHELL, TONY 2003 forthcoming 'Migration, Memory and Hong Kong as a "Space of Transit" in Clara Law's Autumn Moon', Cultural Studies Review, vol. 2, no. 1

MITCHELL, TONY 2001 Clara Law's Farewell China - A Melodrama of Chinese Migration, Hybridity, vol. 1, no. 2, pp. 22-44

MORRIS, MEAGHAN 1998 'White panic or mad max and the sublime', in Kuan-Hsing Chen (ed.), Trajectories: Inter-Asia Cultural Studies, London: Routledge, pp. 239-62

ONG, AIHWA 1999 Flexible Cinizenship: The Cultural Logics of Transnationality, Durham \& London: Duke University Press

PETTMAN, DOMINIC $2000^{\circ}$ The floating life of fallen angels: unsettled communities and Hong Kong cinema', Postcolonial Studies, vol. 3, no. 1, pp. 69-80

Philadelphia Festival of World Cinema program, 1997 wwwlibertyunet.org/pfwc/97fest/ films $/ 97 /$ titles/float.html

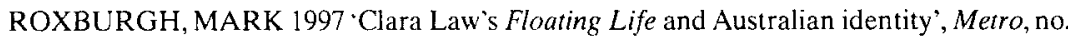
110 , pp. 3-6

STRATTON, DAVID 1998 review of Floating Life, www.theaustralian.com.au/arts/film/ STRATTON, JON 1998 Race Daze: Australia in Identity Crisis, Sydney: Pluto Press TEO, STEPHEN 2001 'Floating Life: the Heaviness of Moving', Senses of Cinema no. 12, February-March (http://www.sensesofcinema.com/contents.01/12/floating.html)

THOMAS, MANDY 1999 Dreams in the Shadows: Vietnamese-Australian Lives in Transition, Sydney: Allen \& Unwin 


\section{Tony Mitchell}

WANG HAIYAN and TONY MITCHELL 2000 Interview with Clara Law and Eddie Fong, Melbourne, 30 June

WOODFORD, H. 1996 Sydney Morning Herald, 11 September

YUE, AUDREY 2000 'Asian Australian Cinema, Asian-Australian Modernity', in Gilbert, Helen et al.. Diaspora: Negotiating Asian-Australia. University of Queensland Press, pp. 190-99

TONY MITCHELL is Senior Lecturer in Humanities and Social Sciences at the University of Technology Sydney.

ADDRESS: Department of Humanities and Social Sciences, University of Technology Sydney, PO Box 123, Broadway, NSW 2007, Australia. Email: tony.mitchell@uts.edu.au 


\section{Ethnic and Racial Studies}

\section{Publisher: Routledge, part of the Taylor \& Francis Group}

38 Issues available online, from January 1998 to January 2003

Subs indicates you have subscription access courtesy of:

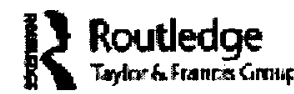

University of Technology, Sydney

Not Available indicates issue not available in electronic format.

Please refer to the publisher.

Trial click on this icon below for a free trial.

\section{Volume 27}

Number 2

Number 1

\section{Volume 26}

Number 6

Number 5

Number 4

Number 3

Number 2

Number 1

\section{Volume 25}

Number 6

Number 5

Number 4

(Beyond Difference)

Number 3

Number 2

Number 1

\section{Volume 24}

Number 6

Number 5

Number 4

Number 3

Number 2

Number 1
January 2003 subs

January 2003 Subs

November 2003 Subs

September 2003 subs

July 2003 Subs

May 2003 Subs

March 2003 subs

January 2003 subs

November 2002 subs

September 2002 subs

July 2002 subs

May 2002 Subs

March 2002 subs

January 2002 subs

November 2001 Subs

September 2001 subs

July 2001 subs

May 2001 subs

March 2001 Subs

January 2001 subs

\section{Related Links:}

- Subscription Information

- Editorial Board

- Table of Contents Alerting

- Notes for Contributors

- Terms and Conditions

- Ingenta Select Guidelines for Use

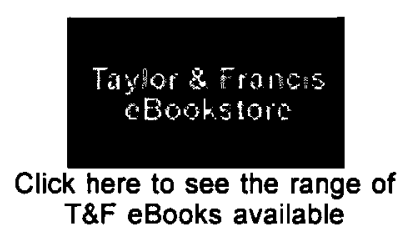

\section{Volume 23}

Number 6

November 2000 5ubs

Number 5

September 2000 subs

(Gender and Ethnicity)
Number 4
July 2000 Subs
Number 3
May 2000 Subs

(Hindutva Movements in the West: Resurgent Hinduism and the Politics of Diaspora)

Number 2

March 2000 Subs

Number 1

January 2000 Subs 


\section{Volume 22}

Number 6

November 1999 subs

Number 5

September 1999 Subs

Number 4

July 1999 subs

Number 3

May 1999 Subs

Number 2

March 1999 subs

Number 1

January 1999 subs

\section{Volume 21}

Number 6

Not Available

Number 5

September 1998 Subs

Number 4

July 1998 Subs

Number 3

May 1998 Subs

Number 2

March 1998 subs

Number 1

January 1998 subs 


\section{Journals}

Wednesday 17 , March

Journals Listings

Printer friendly page

Home

Alphabetical Listing

Journals by Subject

Journal Resources

Advertising

Contacts

Customer Services

E-mail Contents Alerting

Featured Titles

Feedback

New Journals

Office Locations

Online Journals

Pun with Us

Subscription Information

Special Issues

Special Sales

Information

About Us

Books

Site Map

Taylor \& Francis Group

Advice and instructions to contributors:

Click here to check your article status

The editors of Ethnic and Racial Studies welcome the submission of articles on any aspects of race, ethnicity, nationalism and related topics. Articles that are submitted must be original and should not be simultaneously under consideration - either in whole or in part - for publication Articles that are submitted must be original and should not be simultaneously under consideration - either in whole or in part - for publication
eisewhere. Authors are advised that submissions are referred to specialist readers and that some revision may subsequently be required before the elsewhere. Authors are advised that submissions are referted to specialist readers and that some revision may subsequently be required before article is accepted for publication. Submissions are refereed anonymously. To facilitate this anonymous refereeing, authors should ensure that neither their name nor address appears on the front page of their article, or anywhere within it. A detachable sheet on one copy of the articie could, sheet will remain on file.

Authors will be required to conform fully with the approved style of the journal, as set out below. They should note the statement of editorial policy of the journal preceding these instructions. Critical comments on articles previously published in the journal are welcome. However, it is not the policy of the journal to publish translations of articles which have already appeared in a foreign language that should be accessible to most of an educated and interested readership.

The preferred length of articles is between 5,000 and 8,000 words or word equivalents, including all material, and with a maximum of 10,000 . Authors are required to include an ABSTRACT of their article of up to 150 words maximum and up to six keywords, suitable for indexing and online search purposes; these should be typed on a separate page.

Articles should be addressed to

Martin Bulmer.

Ethnic and Racial Studies,

Department of Sociology,

University of Surrey,

Guildtord,

Surrey,

GU2 7XH, UK

Tel: +44 (0)1483 689457 Fax: $+44(0) 1483689457$

Email: ethnicesoc.surrey.ac.uk

Typescripts Authors are required to submit THREE copies of their article. The editors do not undertake to retum rejected typescripts. Articles should be typed or printed on one side only of white paper, either A4-size or $21.6327 .9 \mathrm{~cm}(8.5311 \mathrm{in}$.), and should be double-spaced throughout, including Notes and list of References. Wide margins should be left all around the text on each page, including at least $4 \mathrm{~cm}$ (1.6 in.) on the left-hand margin. All pages, including Notes, References and tables, should be numbered. If printing, ensure a good-quality product. If printing from a modern word-processor, avoid tiny point-sizes and esoteric typefaces, which often make the task of copy preparation more difficult: a standard typeface (such as Ariel or Times New Roman) is preferred. The first paragraph of each section should start at the lefthand margin; the first line of subsequent paragraphs should be indented. Articles should not be submitted via email, and will not be accepted if sent in this way.

Style Abbreviations and technical terms must normally be explained in the text; however, if the former are numerous, they may be listed separately after the text of the article. Quotations should be enclosed with single quotation marks. Substantial quotations of forty or more words should be indented and cited without quotation marks. Double quotation marks should be used between single ones and in indented matter. Where part of a indented and cited without quotation marks. Double quotation marks should be used between single ones and in indented matter. Where part of a quotation is italicized it should be indicated whether this was in the original version or has been added for emphasis (e. 9., Messina 1989, p. 24, emphasis in original; or: Messina 1989, p. 24, emphasis added). Italicization should be indicated in the text by typing or printing in italics or by underlining. The omission of matter within quoted text should be indicated by ellipsis marks (...).

If section headings and subheadings are used, their hierarchy of importance should be clear and consistent. A hierarchy of headings and subheadings should not normally exceed three levels. Section headings should not be underlined: if possible, they subheadings should not normally exceed three levels. Section headings should not be un
should be emboldened. Subheadings should be typed or printed in italics or underlined.

Authors should use gender-free language, avoiding masculine terms when the intention is to cover both genders. However, this instruction should not be followed at the expense of committing grammatical solecisms; where there is a temptation to do this, the sentence should be reformulated.

As far as possible, Ethnic and Racial Studies follows the spelling conventions of the current edition of The Concise Oxford Dictionary, including such matters as accents. Where alternatives are given, ERS prefers the first one. 'Ize/ization' suffixes should be used in preference to 'ise/isation' ones, although note 'anatyse' and not 'analyze'. 'Focused/_focusing' and 'inquire/inquiry' are preferred to 'focussed/focussing' and 'enquire/enquiry' respectively. Spelling practices must be consistent throughout the article, except that the spelling used by the authors of quoted matter should always be respected; however, do not sprinkle 'sic' throughout text that contains numerous obviously idiosyncratic spellings

The use of upper-case letters should be kept to a minimum. It is editorial policy to use lower-case first letters for 'black/white' (whether as noun or adjective) and for 'blacks'(whites'; this signifies no disrespect whatsoever on the part of the editors towards either group.

Full stops should be used after abbreviations (p., pp.) but not after contractions ( $\mathrm{Dr}, \mathrm{Mr}, \mathrm{St}$ ) or acronyms (NATO, UNESCO) or universally identifiable abbreviations (BBC, MP, USA). Note especially 'ed.' but 'eds', 'vol.' but 'vols', and 'no.' but 'nos'. Conventions to be followed concerning dates are: 8 July 1980; on 8 July; on the 8th; the 1980s [no apostrophe]; the eighties; the twentieth century; twentieth-century authors; the 191418 war, between 1914 and 1918. Numbers of 100 or more should be written as numerals, with appropriate commas if 1,000 or more, unless they begin a sentence. Numbers lower than 100 should be spelt out, unless they contain a decimal or a fraction, or they are part of a text containing much numerical discussion, or they are percentages not at the beginning of a sentence. 'Per cent' should always be used in textual matter, not 'percent' or '\%'. The latter should generally be used only in the body of tables.

Tables These must be properly titled and numbered consecutively in the order in which they are to appear in the text. Each table should be prepared on a separate page or separate pages at the end of the typed or printed article and its approximate position in the text should be indicated (e.g., 'Table 1 about here'). Authors should consult recent issues of the journal for examples of the format and style of tables that must be followed; particular care should be taken to follow the journal's practices conceming lower- and upper-case usage, italicization and the location of '\%'-signs. The titles of tables should be in italics, as should the titles of figures. Bold or Roman capitals shouid NOT be used.

Diagrams Diagrams, including graphs and maps, should be camera-ready and as clear and simple as possible and be kept to the necessary minimum. They must all be referred to as 'Figure' and must have their own title; they too should be numbered consecutively in the order in which they are to appear and their approximate position should also be indicated in the text. It is preferable that maps be purpose-drawn to include only those features referred to in the text; if not, the source of a map must be cited. Necessary copyright permission for the reproduction of any already published diagram must have been obtained by the author or authors and the editors and publishers will want documentary evidence to that effect.

Electronic submission of illustrations

Contributors are welcome to submit diegrams and other illustrations as electronic files (as TIFs preferably, or JPEGs). However, it is very important that if contributors are to supply images electronically, these must be scanned in at least 300 dpi (that is dots per inch) in order to produce an that if contributors are to supply images electronically, these must be scanned in at least $300 \mathrm{dpi}$ (that is dots per inch) in order to produce an acceptable qualihy of image. Some scanners cannot achieve this resolution and although a scanned image may look acceptable on a PC screen, may not reproduce well on the proofs or in the final published issue, unless the resolution used is at least 300 dpi - this applies particularly for black and white photographs. Any irnages downloaded from the Internet, for example, are usualiy not usable. Rather than sending in a low

Textual references Unless an article cites many primary sources and/or legal cases, referencing in the text should be set within parentheses 
(round brackets) using the so-called Harvard system of author(s), year of publication and (where appropriate) page number(s). These references should be inserted into the text as close as possible to the relevant point as is consistent with clarity and legibility. The usages contained in the following various examples should be followed as appropriate; these cover all major situations and the point being demonstrated is made explicitly where it is not immediately obvious.

- As Dollard (1957) argues; Dollard's (1957) classic study; (Perrineau 1985)
- (Messina 1989, pp. 23-6) - use the minimum number of digits in page numbers, except between '10' and '19', '110' and '119', etc. (pp. 211-18); referencing to individual chapters with inclusive page numbers in the edition being cited, rather than to chapter numbers, is preferred

- (Banton 1987a; 1987b) - two or more references to works by the same author published in the same year should be distinguished in this way

(Banton 1983; 1987a) but (Banton 1983, p. 104; Banton 1987a, p. 129) - omit the author's surname after the first reference only if he or she is

the only one being cited within a set of parentheses and if only years of publication but not page numbers are being used in all instances

criterion only when citing differently authored publications from the same year

- (Butler and Stokes 1974; Himmelweit et al. 1981) - works by up to three co-authors should cite the surnames of all co-authors, while those

with four or more co-authors should be cited using only the surname of the first, followed by 'et al.'

The corresponding list of References should be typed or printed separately double-spaced at the end of the article beginning on a new page and titled merely 'References'; this title should be left-justified. The list should be alphabetical by surname of author or first co-author and should be in the style of the following examples. Contributors should particularly ensure that they follow these practices with respect to the use of punctuation and lower- and upper-case letters. It is important to include, where they exist, part numbers as well as volume number of cited journals and inclusive page numbers of material from joumals and edited collections. It is also important to provide any subtitle of a book or an article, as weil as the forenames and/or initials of authors of cited material, as given in the original reference. Contributors are also requested to take care that only those references cited in the text appear in the list of References and vice versa. General bibliographies should not be given.

ANTHIAS, FLOYA 1992 'Connecting "race" and ethnic phenomena', Sociology, vol. 26, no. 3, pp. 421-38

BANTON, MICHAEL 1983 Racial and Ethnic Competition, Cambridge: Cambridge University Press

- 1987a Racial Theories, Cambridge: Cambridge University Pres

- 1987b 'The beginning and the end of the racial issue in British politics', Policy and Politics, vol. 15, no. 1, pp. 39-47

BUTLER, DAVID and STOKES, DONALD 1974 Political Change in Britain: The Evolution of Electoral Choice, 2nd edn, London: Macmillan

CHARLES, MARIA 1990 'Occupational Sex Segregation: A Log-linear Analysis of Patterns in Twenty-five Industrial Countries', PhD dissertation Department of Sociology, Stanford University, Stanford, CA

DOLLARD, JOHN 1938 Caste and Class in a Southern Town, 4th edn, Madison, Wi: University of Wisconsin Press [1st edn, New Haven, CT: Yale University Press, 1937] immigrants', in Khalid Koser and Helma Lutz (eds), The New Migration in Europe: Social Constructions and Social Realities, Basingstoke:_Macmillan, pp. 199-223

HIMMELWEIT, HILDE T, et al. 1981 How Voters Decide. A Longitudinal Study of Political Attitudes and Voting Extending Over Fifteen Years, London: Academic Pross

MESSINA, ANTHONY M. 1989 Race and Party Competition in Britain, Oxford: Clarendon Press

PERRINEAU, PASCAL 1985 'Le Front National: un électorat autoritaire', Revue Politique et Partementaire, no. 918, pp. 24-31

SOMBART, WERNER 1976 Why Is There No Socialism in the United States?, London: Macmillan [first published in German in 1906]

THOMAS, J. J. R. 1985 'Rationalization and the status of gender divisions', Sociology, vol. 19, no. 3, pp. 409-20 WALVIN, JAMES 1982 'Black caricature: the roots of racialism', in Charles Husband (ed.), 'Race' in Britain: Continuity and Change, London:
Hutchinson, pp. $59-72$

Give only the first named place of publication if more than one are listed on the title-page of a book. It is helpful if the names of American towns or cities (except New York) are followed by the Post-Office-approved two-letter abbreviation of the state concerned; e.g., Cambridge, Massachusetts, should be identified as 'Cambridge, MA'. Publications with up to three co-authors should be referenced as in the Butler/Stokes example; those with four or more co-authors should be referenced as in the Himmelweit example.

Internet references References in the text to internet resources should be made in the usual way with the name of the individual author of the material (e.g., Solomos 1999) or of the organization maintaining the website, followed by the date. Information about the electronic location of the information should be given in the References at the end of the article. All internet references should be integrated into the alphabetized list of textual references at the end of the article, following these conventions: they should be listed in alphabetical orcer of author (if an article in a journal) or the holder of the website (if an organization); cite the full website address, and give the date on which the site was accessed. If a website has been cited without being accessed, it should be cited with 'n.ac.'

Articles published in alectronic joarnals should be citedlin the following format:

SOLOMOS, JOHN 1999 'Social research and the Stephen Lawrence Inquiry', Sociological Research Online, vol. 4, no. 1, [followed by paragraph number if citing a particular point in the text.) More information about ways of citing electronic material may be found in Janice $R$. Walker and Todd Taylor, The Columbia Guide to Online Style (New York: Columbia University Press, 1998), Part 1, 'Citation'.

See also Graham Shields and Graham Walton, Cite Them Right! How To Organise Bibliographical References, particularly the section on how to cite Electronic Information at:

http://www.unn.ac.uk/central/isd/cite/eiec.htm

Notes These should be kept to the necessary minimum, titled 'Notes', and should be used only where inclusion of the material in the text would disturb the flow of the article. They should be numbered sequentially throughout the article and be typed or printed double-spaced separately immediately after the text, beginning on a new page.

Book reviews These are normally solicited by the Editors. It is therefore advisable not to prepare book reviews without prior consultation with them. Books for review should be sent to the Managing Editor.

Proofs Page-proofs of accepted articles will be sent to contributors by the publishers. Corrected proofs must be returned to the Managing Editor of Ethnic and Racial Studies as soon as possible after receipt and by or before the date indicated by the publishers when they send out authors' proofs. The attention of authors is drawn particularly to the fact that no substantive changes are permissible at proof stage; rigid adherence to this principle will be maintained and authors are accordingly urged to ensure that their submitted articles are error-free.

Copyright It is a condition of publication that authors vest the copyright of published articles and book reviews in the publishers, Taylor \& Francis Ltd. This enables the publishers to ensure full copyright protection and to disseminate the article, and the journal, to the widest possibie readership in print and electronic formats as appropriate. Authors may, of course, use the article elsewhere after publication provided that prior permission is obtained from Taylor \& Francis Ltd. Authors must ensure that copyright material which they themselves cite is being used with the permission of the copyright holder and the editors may want documentary evidence to that effect

Libel Attention is drawn to the fact that the acceptance of an article, report or review is conditional upon its author or authors having ensured that it contains nothing which is unlawful. Agreement by authors to the publication of their material necessarily implies acceptance of this condition

Early Electronic Offprints: Corresponding authors can now receive their article by e-mail as a complete PDF. This allows the author to print up to after publication. Additional copies of the journal can be purchesed at the author's preferential rate of $\varepsilon 15.00 / \$ 25.00$ per copy. 
Subject: Research publications

From: Tony Mitchell <tony.mitchell@uts.edu.au>

Date: Thu, 19 Feb 2004 12:44:10 +1100

To: Maryanne.Hozijan@uts.edu.au

Hi Maryanne - here's details of my 2003 research publications - do you also need hard copies of these? Cheers, Tony

\section{Book Chapters}

Indigenising Hip Hop: an Australian Migrant Youth Subculture', in Melissa Butcher and Mandy Thomas (eds) Ingenious: Youth Culture in Multicaltural Australia, Sydney: Pluto Press, 2003, 198-214.

'Doin' Damage in My Native Language: Resistance Vernaculars in Hip Hop in France, Italy and Aotearoa/New Zealand', in Harris M. Berger and Michael Thomas Carroll (ed.) Global Pop, Local Language, Jackson: University of Mississippi Press, 2003, 3-18.

Entries on 'National identity in rock music' and 'New Zealanders: Pop and Rock' in John Whiteoak and Aline Scott-Maxwell (eds) Currency Companion to Music and Dance in Australia, Sydney; Currency House Inc., 2003, 453-455, 457-458.

\section{Refereed Journal Articles}

'Australian Hip hop as a Subculture', Youth Studies Australia, vol. 22, no.2, June 2003, 40-47. 'Migration, Memory, and Transitional Identities in Clara Law's Autumn Moon,' Cultural Studies Review, vol. 9. no.1, May 2003, 139-160.

'Clara Law's Floating Life and Hong-Kong Australian "Ilexible citizenship", Ethnic and Racial Studies vol. 26 no.2, March 2003, 278-300.

\begin{tabular}{|l|l|}
\hline Part 1.1 & $\begin{array}{l}\text { Content-Type: } \\
\text { Content-Encoding: quoted-printable }\end{array}$ \\
\hline
\end{tabular}

